Jorge E. Aceves

Renée de la Torre

Patricia Safa*

\title{
Fragmentos urbanos de una misma ciudad: Guadalajara
}

El propósito del artículo es reflexionar sobre las transformaciones recientes en Guadalajara y destacar algunos de los retos que actualmente enfrenta esta ciudad. Proponemos acercarnos a su heterogeneidad; para realizar este recorrido, $y$ como tipificación de espacio habitado, se distinguen cuatro Guadalajaras: la ciudad concéntrica, la ciudad dividida, la ciudad fragmentada y la ciudad flujos. Este viaje nos obliga a elaborar una interpretación crítica de las múltiples representaciones de la identidad de la ciudad, $y$ a delinear algunos nodos problemáticos en el presente que sería necesario resolver para imaginar su futuro.

Palabras clave: ciudad, heterogeneidad urbana, identidad urbana, zona metropolitana de Guadalajara.

- Los autores son profesores investigadores del Centro de Investigaciones y Estudios Superiores en Antropología Social (CIESAS) en Occidente.

jaceves@ciesasoccidente.edu.mx
In memoriam Arquitecto Daniel Vázquez

Podría decirte de cuántos peldaños son sus calles en escalera, de qué tipo los arcos de sus portales, qué chapas de zinc cubren los techos; pero ya sé que sería como no decirte nada. La ciudad no está hecha de esto, sino de relaciones entre las medidas de su espacio y los acontecimientos de su pasado.

Las ciudades son un conjunto de muchas cosas: memorias, deseos, signos de un lenguaje; son lugares de trueque, como explican todos los

libros de historia de la economía, pero estos trueques no lo son sólo de mercancías, son también trueques de palabras, de deseos de recuerdos.

Italo Calvino

\section{Introducción}

Hacer un ensayo sobre la identidad de Guadalajara nos enfrenta a varios retos. El primero es decidirnos sobre cuál Guadalajara podemos hablar. Pues hay tantas Guadalajaras como los recorridos que la transitan, los recuerdos que la pueblan, las narrativas que la describen, o las múltiples maneras en que la habitan los tapatíos. El 
segundo reto que enfrentamos es describir la identidad, pues ésta es tan multifacética como la diversidad de sus habitantes. Sin embargo, Guadalajara - la de Jalisco, México- es una en cuanto a territorio ocupado y negociado, y es múltiple en cuanto lugar practicado y disputado.

En este trabajo nos interesa reflexionar sobre las transformaciones más recientes que ha sufrido la ciudad y destacar algunos de los retos que actualmente enfrenta. Dicho ejercicio lo realizaremos desde una perspectiva antropológica, es decir, acercándonos a la ciudad como espacio construido y existencial donde puede sensibilizarse lo amado, lo odiado, lo deseado, lo temido (Delgado, 1999: 40). Partimos del supuesto de que la ciudad antropológica está trazada por lugares cargados de identidad, historia y relación; pero también está constituida por pasajes transitados, vividos en términos de distancias, movimientos, flujos y redes. Ambos aspectos se ponen en intersección para generar las características de la urbanización. Desde la antropología, nos interesa estudiar cómo los habitantes de las ciudades experimentan y se insertan en tramas relacionales, enmarcadas en el espacio, la distancia y el tiempo. El espacio construido es materialización física de lo que perdura, pero también un escenario inestable y dinámico que acompaña los cambios en la vida cotidiana de los urbanitas. La antropología también debe dar cuenta de las movilidades, porque es en ellas, por ellas y a través de ellas como las personas pueden entretejer sus propias personalidades, todas ellas hechas de trasbordos y correspondencias, pero también de traspiés y de interferencias (Delgado, 1999: 45).

Las ciudades también están hechas de recuerdos, nostalgias, narrativas, miedos y deseos. Martín Barbero compara las ciudades con la escritura del palimpsesto: "Texto borrado por el tiempo que vuelve a emerger sobre las entrelíneas con que escribimos el presente". La ciudad está formada por capas tectónicas de memorias, con graduaciones e intensi- 
dades distintas que prefiguran o sepultan el presente, pero que también se tornan borrosas en las actualizaciones del olvido. Sin embargo están ahí, con mayor o menor intensidad. En Guadalajara el pasado y el presente se entretejen; por eso da la impresión de ser una ciudad de ciudades superpuestas. Se le puede recorrer a partir de su historia o analizar los cambios que ha sufrido a partir de la década de los setenta, que la convirtió en una metrópoli; también podemos hablar de ella como una ciudad de flujos, siempre en movimiento. Lo que nos interesa es acercarnos a su heterogeneidad y evitar, en la medida de lo posible, las perspectivas parciales para dar paso a su diversidad compleja. La ciudad histórica será la primera parada de esta ruta, lo que nos permitirá analizar sus divisiones socio-espaciales del pasado. La modernización de Guadalajara será la siguiente estación para entenderla dividida y segmentada, y la ciudad comunicacional (flujos) nos conduce a la última parada: la de la fragmentación. Para realizar este recorrido, y como tipificación de espacio habitado, decidimos distinguir cuatro Guadalajaras: la ciudad concéntrica, la ciudad dividida, la ciudad fragmentada y la ciudad flujos. Este viaje nos obliga a elaborar una interpretación crítica de las múltiples representaciones de la identidad de la ciudad, y a delinear algunos nodos problemáticos en el presente que sería necesario resolver para imaginar su futuro. 


\title{
I. La ciudad concéntrica
}

\begin{abstract}
En Olinda, el que lleva una lupa y busca con atención puede encontrar en alguna parte un punto no más grande que la cabeza de un alfiler donde, mirando con un poco de aumento, se ven dentro los techos, las antenas, las claraboyas, los jardines, los tazones de las fuentes, las franjas rayadas que cruzan las calles, los quioscos de las plazas, la pista de las carreras de caballos. Ese punto no se queda ahí: al cabo de un año se lo encuentra grande como medio limón, después como una gran seta, después como un plato sopero. Y hete aquí que se convierte en una ciudad de tamaño natural, encerrada dentro de la ciudad de antes: una nueva ciudad que se abre paso en medio de la ciudad de antes y la empuja hacia fuera.
\end{abstract}

Italo Calvino

La Guadalajara fundacional es la que hoy conocemos como centro de la ciudad o - recientemente - como centro histórico, fundada por españoles en 1542 en el Valle de Atemajac, a un lado de dos poblaciones indígenas: Mezquitán (habitado por indios texcuexes) y Mexicaltzingo (por indios mexicanos y algunos tarascos). Casi simultáneamente a la fundación de Guadalajara, en la parte oriente del río se fundó otro pueblo indígena (cuyos pobladores eran los indios de Tetlán), llamado Analco(Chávez Hayhoe, 1953: 59). Cada población, incorporada como barrio a partir de 1667, tenía su propio gobierno y era independiente de las otras.

La geografía simbólica de Guadalajara correspondía a una organización concéntrica. La ciudad se organizaba en torno a su plaza central o mayor (hoy Plaza de Armas), que albergaba la Catedral, el Real Palacio, la Real Caja, la casa del Ayuntamiento y los portales donde se encontraban los comercios. Este cuadro central era tanto un lugar que concentraba el encuentro de los pobladores como los centros del poder. A su vez, cada barrio tenía su propia organización alrededor de un espacio central de confluencia de sus habitantes: templo, plaza, mercado, cantina y comercios, 
formaban en sí mismos un núcleo referencial para la organización vecinal. Representaba un marco de pertenencia de las identidades barriales y un lugar de encuentro entre los vecinos. El barrio, como lo señala Martín Barbero, ha venido funcionando como:

[...] el gran mediador entre el universo privado de la casa y el universo público de la ciudad, un espacio que se estructura con base en ciertos tipos específicos de sociabilidad y en últimas de comunicación: entre parientes y entre vecinos. El barrio proporciona a las personas algunas referencias básicas para la construcción de un nosotros, esto es, de "una socialidad más ancha fundada en los lazos familiares y al mismo tiempo más densa y estable que las relaciones formales e individualizadas impuestas por la sociedad” (Martín Barbero, 1987: 217).

Esta geografía cultural concéntrica, mediada por las identidades barriales, ha sido muy complementaria, pues el barrio, aunque goza de cierta autonomía para regir y organizar la vida cotidiana, es el mediador e integrador de los habitantes a la ciudad, y a la vez la ciudad se alimenta de estas identidades barriales para conformar su propio marco de referencia de representación simbólica del nosotros (De Certau, 1996).

Tanto los barrios como el primer cuadro histórico de la ciudad son por excelencia lugares antropológicos que funcionan como escalas de la organización de la vida social y de la representación de una colectividad: el centro histórico, el barrio, la plaza, el templo, la escuela, el mercado, el club, los monumentos (Augé, 1993). Los barrios han sido definidos por Michel de Certau (1996) como los espacios intermedios-intermediarios entre el individuo y la ciudad; entre las relaciones íntimas y los trámites anónimos propios de la ciudadanía metropolitana. Son espacios que articulan la vida privada, la de la familia y los seres que comparten el hogar, con relaciones sociales de interacción cotidiana. Estas relaciones 
establecen el contrato que sirve de motor a la sociedad: la continuidad de la confianza en el otro diferente pero cercano. Es en el territorio vecinal donde sus miembros (individuos, familias y clanes) logran reconocer en la interacción cotidiana aquello que los vincula en el contexto de la diversidad cultural. La vecindad es, a la vez, una escala de interacción humana, comunitaria y ciudadana, enmarcada en un espacio discontinuo como lo es la ciudad.

Por su parte, a lo largo de la historia de Guadalajara, los centros históricos (ya no sólo hay uno, sino que también debemos incluir los de Zapopan, Tlaquepaque y Tonalá e incluso los de los barrios tradicionales, los cascos centrales de los pueblos que han sido integrados a la mancha urbana, y el caso del fraccionamiento Chapalita cuya glorieta es habitada los fines de semana como lugar de encuentro y socialización), con sus plazas, kioscos y jardines, son lugares cargados de identidad, de memoria, de historia, de múltiples trayectorias de individuos y grupos que dejaron un legado cultural a los habitantes del presente. Son lugares que resguardan y mantienen vivas y vigentes las tradiciones, los sabores, los oficios tradicionales, mitos y leyendas urbanas, pero también maneras de interactuar y de habitar la ciudad. Son lugares diseñados para el encuentro y la convivencia de la diversidad social pues están abiertos para todo tipo de habitante que ahí se congregue. Son lugares habitados como plaza pública, como lugar de encuentro, de sociabilidad de intercambio y son usados creativamente por los habitantes para experimentar distintas maneras de estar juntos. La plaza central —algunos parques y jardines públicos— sigue siendo hoy en día el lugar de las manifestaciones cívicas y políticas, ahí confluyen los ciudadanos que se manifiestan para hacer valer los derechos de los ciudadanos que habitan las ciudad (es el lugar de las marchas de protesta, los plantones y huelgas de hambre, así como para el cierre de los mítines políticos). 
En los centros históricos prevalece un tiempo intersticial, pues se ponen en intersección el tiempo memorable: la tradición y su memoria, con el tiempo presente que renueva el pasado y expresa los deseo futuros, y cuya dinámica le otorga nuevos usos, significados y funcionalidades a lo tradicional. Por ejemplo, los centros históricos, al albergar los principales templos, en cuyo seno se resguardan los símbolos religiosos fundacionales de la devoción católica, mantienen vivos los rituales ancestrales que convocan a la renovación de la religiosidad popular y el ritual masivo. La Romería a la Virgen de Zapopan es un caso excepcional para entender el lugar de encuentro de la diversidad identitaria de Guadalajara. Hoy en día existen más de 200 compañías danzantes que participan en la Romería de la Virgen de Zapopan. Las compañías danzantes se conforman en los distintos barrios de la zona urbana, que representan distintas maneras de vivir la experiencia urbana: antiguos pueblos indígenas vecinos o integrados a la ciudad, antiguos barrios populares, colonias y fraccionamientos residenciales, nuevos asentamientos irregulares. La experiencia de participar en las compañías danzantes permite que los nuevos pobladores urbanos construyan formas de sentirse y saberse parte de la ciudad, y a través de ellas los habitantes están reformulando su identidad (barrial y ciudadana), resemantizando una tradición católica y reinventándose un linaje indígenaurbano, aunque en su mayoría los danzantes sean mestizos (véase De la Torre, 2001).

Pero los centros históricos también son espacios donde se lucha por el reconocimiento de la diversidad cultural, es el lugar donde distintos ciudadanos se expresan de manera creativa para conquistar visibilidad, sobre todo en lo que se refiere a identidades minoritarias, social y culturalmente estigmatizadas y negadas por la ciudad, por ejemplo, la 
marcha anual por la diversidad sexual, ${ }^{1}$ las manifestaciones artísticas juveniles (el mejor ejemplo es la manifestación de los jóvenes que recientemente organizaron una fiesta rave en la Plaza de Armas), ${ }^{2}$ o el festival cultural de los migrantes indígenas asentados en la ciudad, que reivindican la presencia de la diversidad étnica que habita la ciudad. ${ }^{3}$ Estas manifestaciones culturales buscan renovar el sentido cultural tradicional, que excluye cotidianamente la manifestación y la visibilidad de identidades culturales, en un nuevo territorio que los acoja. Como lo interpreta Amalia Signorelli (2001), estas manifestaciones culturales tienen como intención "hacer que las calles sean inmediatamente, aquí y ahora, como las quiere". No es una coincidencia que estos pobladores sufran cotidianamente el rechazo de los sectores más conservadores de la ciudad, los cuales buscan imponer un imaginario tradicional que se niega a

I. Desde 1994, año con año, y en concordancia con otras ciudades del mundo, asociaciones civiles como el Comité Lésbico Gay de Occidente, el Comité Humanitario del Esfuerzo Compartido Contra el Sida (Checos) La Red Cultural Cobalto, el Tianguis Cultural de Guadalajara, los Osos Tapatíos, la Brigada Callejera de apoyo a la Mujer y el Proyecto Azomally acompañan a un nutrido contingente de individuos gays y lésbicos de la ciudad para celebrar la marcha por los derechos a la diversidad sexual, en un recorrido que sale de Chapultepec, por la avenida Hidalgo y cierra con un mitin-festival en la Plaza Fundadores.

2. Con el objetivo de "poner fin a la estigmatización de las expresiones de la cultura juvenil", y de manifestarse en contra de los operativos represivos en contra de las fiestas raves, el 12 de mayo de 2002, la Plaza de Armas se convirtió en escenario de una fiesta de música electrónica donde la diversidad de identidades juveniles, representada por cinco mil jóvenes, convivió y bailó al ritmo de los DJ. En ese mitin se propuso instaurar el 4 de mayo como Día de la Expresión Juvenil (Público, 13 de mayo de 2002).

3. A pesar de que los habitantes y las autoridades de la ciudad de Guadalajara niegan e ignoran la presencia de los indígenas en la ciudad (Martínez Casas, 200I: 107), en Guadalajara, aunque son una minoría poblacional, habitan distintos grupos indígenas que cargan sus riquezas culturales étnicas: otomíes, mixtecos, nahuas, purépechas, otomíes, wixarritarí, triquis, entre otros. El 8 de septiembre de 2002, en la Plaza de las Sombrillas, se celebró con danzas, conciertos, comida autóctona y venta de artesanías, el Festival de Migrantes Indígenas, propiciando una convivencia intercultural entre los habitantes de Guadalajara (indígenas y mestizos), y teniendo como objetivo el encuentro profundo con los pueblos indígenas, que son parte sustantiva de la cultura mexicana (Público, 10 de septiembre de 2002). 
los cambios incorporados por la vitalidad de los jóvenes; un imaginario criollo que se niega a la presencia indígena; un imaginario heterosexual e incluso machista que no quiere aceptar la diversidad sexual que se practica en la ciudad. ${ }^{4}$ Como lo señala Jesús Martín Barbero (1994), el grupo que en un momento dado decide convertir la plaza en "nuestro" lugar, conquista el lugar en un territorio de identidad (p. 115). Hoy por hoy, el centro histórico, sigue siendo la plaza pública por excelencia, mantiene el encuentro y el enfrentamiento entre los poderes públicos y las acciones de la sociedad civil. Es una arena donde se lucha por la adscripción, el reconocimiento y la valoración de las identidades estigmatizadas.

\title{
2. La ciudad dividida
}

\begin{abstract}
A las otras ciudades les queda en el medio el viejo cerco de murallas, bien apretado, del que brotan resecos los campaniles las torres los tejados las cúpulas, mientras los barrios nuevos se desparraman alrededor como saliendo de un cinturón que se desanuda.

Italo Calvino
\end{abstract}

Las ciudades no son sólo escenarios de encuentro e interacción en la diversidad, sino también lo son de las desigualdades y de las zanjas materiales y culturales que dividen y segregan dichas desigualdades. Si algo diferencia esta ciudad de otras, es que es una ciudad que se erigió bordeada al oriente por una impresionante barranca que protegía a

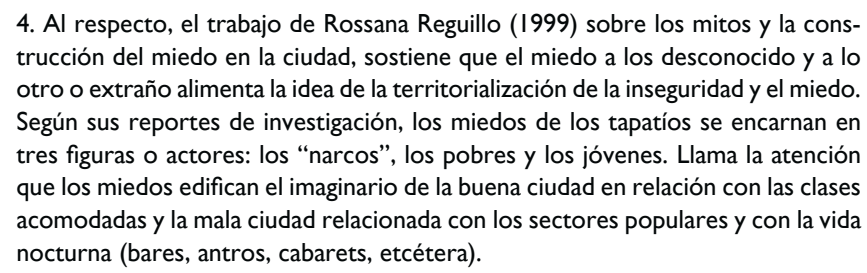


los españoles de los ataques de los indios "chichimecas", y dividida internamente por el río San Juan de Dios; desde su fundación, los 64 españoles se asentaron al lado poniente del río. Durante los siglos XVIII y XIX, el río cortaba a la ciudad en dos: al poniente había quedado el centro histórico, alrededor del cual vivía la burguesía local formada, en general, por una población criolla, y en sus márgenes se encontraban los barrios de Mezquitán y Mexicaltzingo. Y al oriente se confinaba la Guadalajara indígena y pobre: la clase trabajadora que abastecía a los españoles. Durante siglos, el río fue lugar de recreo y paseo de su alta burguesía; pero durante la Colonia y hasta el siglo XIX, la ciudad se vio azotada en varias ocasiones por el cólera, y el río San Juan de Dios era una fuente insalubre que contribuía a la mortalidad de la población. A principios del siglo XX, durante el Porfiriato y como parte de las celebraciones del centenario de la Independencia, la ciudad cobró una nueva fisonomía: el río es entubado y ocultado bajo la Calzada Independencia. Esta avenida funcionó durante mucho tiempo como una frontera cultural $^{5}$ entre dos poblaciones urbanas que, con base en criterios étnicos, económicos, de clase, morales y funcionales, trazaba dos ciudades perfectamente demarcadas: "de la Calzada para acá" (al poniente) y "de la Calzada para allá" (al oriente). ${ }^{6}$ Así, la frontera diferenciaba clasistamente a la ciudad en dos poblaciones: "los de la Calzada para allá" ("el peladaje", los pobres, feos e incultos) y "los de la Cal-

5. El concepto de fronteras culturales permite explorar el campo de la cultura vinculado al espacio de las representaciones sociales. Las fronteras culturales no se limitan a las fronteras físicas, geográficas o políticas, sino a su representación interiorizada y grupalizada, a partir de la cual se distinguen las categorías de identidad social. Las fronteras culturales son el lugar donde la interacción produce diferencias y semejanzas, pero son también las arenas de lucha por la simbolización de las prácticas sociales (Rosaldo, 1991).

6. John Walton (1978) definió la ciudad de Guadalajara como "la ciudad dividida", pues encontró que la ciudad estaba partida en dos territorios que demarcaban la separación y funcionamiento diferencial de las clases sociales: al oriente la clase obrera $y$ al poniente las clases medias $y$ altas de la ciudad. 
zada para acá" ("la gente bien", bonita y educada). Ya desde la época porfiriana, la parte occidental era casi tres veces mayor, y más pudiente, que la del oriente. $\mathrm{Al}$ poniente de la Calzada se edificaron las avenidas arboladas, con sus elegantes mansiones, los monumentos históricos, y se asentaron los antiguos habitantes y los prósperos inmigrantes europeos: la burguesía y las clases acomodadas; en resumen, allí se albergaba "la gente de bien".

A mediados del siglo XX, las clases media y alta comenzaron a abandonar sus casas del centro para vivir en las colonias Francesa, Americana y Moderna. El centro histórico no sólo sufrió el abandono de su pobladores originales y de alcurnia, sino también fue sacrificado (o crucificado) para dar paso a una ciudad que, para abrirse camino al progreso y a la industrialización, requería ofrendar la ciudad habitada por la ciudad transitada.

El centro dejó de ser habitado para constituirse en un lugar de pasaje. A principios de los años cincuenta, dos de sus calles centrales, 16 de Septiembre (de norte a sur) y la Avenida Juárez (de oriente a poniente), se ensancharon y alinearon para constituirse en arterias amplias que facilitaran los flujos rápidos vehiculares hacia el exterior. El centro histórico también dejó de ser visto como el lugar para ser habitado, y se dio paso al diseño del "centro museo" con la construcción de la cruz de plazas. Jorge Camberos, uno de los principales conocedores de la historia urbanística de la ciudad, comentó: "esta cirugía vial [acabó] de romper con la unidad del centro histórico de la ciudad" (véase Núñez Miranda, 1999: 115). Pero la última estocada al centro histórico se dio en los años ochenta con la Plaza tapatía, que según opinión de Fernando González Gortázar: "Fue una irrupción violenta y prepotente de la Guadalajara del poniente —rica y clasemediera- hacia el corazón popular de la Guadalajara del oriente - de escasos recursos, proletaria" (véase Petersen, 1990: 140). 
Los usos de la urbe se transformaron, incrementando la división entre sus dos extremos y su distinción de clases. La ciudad de los ricos y los pobres podía reencontrarse aún en el centro metropolitano y en San Juan de Dios, zonas de espectáculos, cantinas, teatros, cines y cabarets, que de noche recibían a los pobladores del lado poniente para transgredir la moral tradicional y los usos provincianos. Por otro lado, la Zona Rosa, ubicada al poniente, alrededor de la avenida Chapultepec, se convirtió en un lugar exclusivo para el esparcimiento y encuentro de la gente bien de la ciudad. A partir de los años setenta, la fisonomía del lado poniente se modernizó: se construyeron amplias avenidas, centros comerciales -al estillo de los malls de los Estados Unidos-, 7lujosos rascacielos y colonias residenciales al estilo americano, que hacían más evidente el rezago del progreso para el lado oriente. Al oriente de la Calzada, apenas cruzándola por el centro histórico de la ciudad, se ingresaba directamente a la zona roja o de tolerancia; primero estaban los bares y cantinas, seguidos de los burdeles, para llegar directamente a los hoteles de paso. De este otro lado se mantenían los antiguos barrios y todavía más hacia las afueras estaban las reservas de mano laboral de la urbe, territorios "pelones", empolvados y marginales a donde llegaban los recién migrantes del campo a la ciudad. Las élites dejaron de frecuentar el centro como lugar de actividad comercial, de paseo, de encuentro y de diversión: poco a poco los nuevos centros comerciales albergaron las actividades de las élites urbanas. Sin embargo, esto permitió una reapropiación y uso del centro. Por ejemplo, el centro se convirtió en territorio de encuentros homosexuales: las viejas salas de cine, las cantinas, los parques (el más famoso por su nueva vocación es el Revolución), los baños públicos, los campanarios de las iglesias (Carrier, 2002). Los niños de la calle improvisaron albergues en viejos edificios, esquinas, 
portales, e incluso debajo de puentes y alcantarillados en el centro de la ciudad. El centro se convirtió en un refugio de la otredad. Esto provocó localizar los miedos en las zonas pobres y decadentes. El centro, poco a poco, en la medida en que se iba vaciando, fue siendo percibido como un lugar inseguro, peligroso, y que atenta contra el orden moral.

Si bien espacialmente la frontera establecida por la Calzada Independencia ha dejado de ser capaz de contener la división entre las poblaciones pudientes y las pobres de la ciudad, psicológicamente no sólo ha perdido fuerza, sino que se desdobla como lógica que busca aislar, dividir y excluir. El poniente de la ciudad ha dejado de ser un territorio exclusivo para las clases acomodadas, pues los pobres se asentaron en sus periferias, pero el oriente mantiene la misma carencia de infraestructura y atención urbana que la distinguió originalmente. La única novedad para el oriente es que ante la carencia de servicios y asociaciones e instituciones barriales, las iglesias fundamentalistas de tipo evangélico han logrado establecerse con exitosa hegemonía en esa parte de la ciudad. ${ }^{8}$

\section{La ciudad fragmentada}

También yo he pensado en modelo de Ciudad del cual deduzco todas las otras - respondió Marco-. Es una ciudad hecha sólo de excepciones, exclusiones, contradicciones, incongruencias, contrasentidos.

Italo Calvino

A partir de los años setenta, el orden urbano se ve desbordado por los asentamientos irregulares que surgen como hongos alrededor de la ciudad, por lo general en tierras ejidales que carecen de servicios básicos, conformando

8. Véase el caso de la Iglesia de la Luz del Mundo, cuyos templos y colonias crecen a un ritmo impresionante en la zona oriente de Guadalajara (De la Torre, 2000). 
lo que se conoce como cinturones de miseria. La nueva condición de irregularidad, por asentarse sobre terrenos ejidales, es aprovechada por las autoridades locales para extender la irregularidad, no como fase inicial de un proceso de regularización urbana, sino como existencia estructural de marginación (Ibáñez y Vázquez, 1970). En la actualidad casi $20 \%$ de quienes habitan Guadalajara viven en asentamientos irregulares (Cabrales, 2002: 96). Muchos de estos asentamientos no gozan de calles pavimentadas, drenajes, alumbrado público, policía, servicio de transporte, salud, etc. Y esto se agudiza si pensamos que quienes habitan ahí carecen de transporte motorizado, y se les dificulta mucho movilizarse hacia los polos donde pueden ser atendidos o donde pueden exigir apoyos a su precaria situación; también disminuyen sus posibilidades reales para insertarse como ciudadanos y gozar de los beneficios que ofrece vivir en la ciudad. Me refiero a que su situación de precariedad y lejanía del centro de la ciudad les dificulta su inserción como ciudadanos participantes en la vida de la urbe. Pero el barrio popular ya no es el escenario de las relaciones armónicas basadas en lazos de solidaridad, confianza y autoayuda, es también el espacio donde se sufre cotidianamente la violencia urbana, que hace del barrio un territorio internamente fragmentado por la inseguridad cotidiana. La crisis de seguridad y la descomposición del tejido social construido sobre la confianza vecinal, es a la vez un factor de inmovilización hacia el exterior y de fragmentación interna:

La crisis de seguridad afecta e inmoviliza a quienes viven en los barrios populares, obligados a garantizar, en todo momento una presencia en sus casas para evitar depredaciones y robos, y condenados al aislamiento en viviendas donde el equipamiento cultural es mínimo. La movilidad en el tiempo de ocio se reduce $y$, en consecuencia, también se achican las posibilidades de contacto con otros niveles y consumos sociales (Sarlo, 200I: 59). 
Fragmentos urbanos de una misma ciudad: Guadalajara

Por otro lado, desde los años sesenta, el modelo del suburbio americano se empezó a desarrollar a las afueras de la ciudad (Santa Anita, Rancho Contento, Bosques de San Isidro, El Palomar y Ciudad Bugambilias). Pero a partir de los años ochenta las clases medias y altas, movidas por el miedo y la inseguridad, han decidido trasladar sus mundos de vida a guetos exclusivos que, resguardados por múltiples murallas de piedra ofrecen a sus habitantes "seguridad, exclusividad, las facilidades o comodidades, privacidad, contacto con la naturaleza, ubicación y plusvalía" (Ickx, 2002: 132), ejemplo de ello son Valle Real, Puerta de Hierro y Royal Country, entre otros. El nor-poniente y el sur de la ciudad van cobrando una nueva fisonomía del paisaje urbano, conformado por grandes murallas y puertas de ingreso resguardadas por policías y avenidas donde sólo transitan los automovilistas (ejemplo de ello es avenida Acueducto, Juan Palomar y Arias y el sur de López Mateos). Estos fraccionamientos cerrados o exclusivos se han convertido también en la aspiración del modo de vida de las clases medias. Para el año 2000, se habían construido 150 cotos privados, tendencia que no sólo se despliega hacia las clases privilegiadas sino que también más recientemente es ofertada para la "vivienda social" (Ickx, 2002: 126).

Los cotos o fraccionamientos privados van generando una socialidad separada del resto de la ciudad. Algunos de ellos incluyen áreas deportivas, espacios recreativos, clubes privados, e incluso colegios privados. El consumo se realiza gracias a la movilidad que da el automóvil desde la casa a un centro comercial. Dentro de sus barreras recrean su propia manera de vivir en la ciudad, sin necesidad de integrarse a ella, ni de convivir con el resto de sus pobladores: los "otros", los diferentes. Cada casa está equipada para mantener interconexiones globales, a través de la televisión por cable y el uso de Internet. Las categorías de exterioridad e interioridad se van reconfigurando en la relación que generan con lo 
local y lo global. Por un lado, lo exterior se va fortaleciendo en relación con el resto de la ciudad, y por otro lado, se van diluyendo en relación con los flujos globales que desde la interioridad de cada hogar los interconectan con otras realidades. Las dimensiones de la interacción en la alteridad, que define la socialidad utópica de la ciudad, se van debilitando. Existe una voluntad por desvanecer el mundo exterior, al que se percibe como amenazante y peligroso, a la vez que gozar plenamente el mundo interior. La pregunta que surge, entonces, no es solamente por los problemas de vialidad que producen estos cotos para el resto de la ciudad, sino sobre todo urge reflexionar: ¿Qué modelo de ciudadanía generarán estas formas de vida urbana? Una respuesta pertinente es la que ofrece Ickx (2002), quien plantea que el contrato social al interior de estos espacios se da a la manera de un consumidor que paga por sus servicios y los goza, pero que lo inquietante de este proceso de privatización urbana es que provoca "la pérdida de los intereses comunes" (p. 130). Es decir, la privatización urbana produce una fragmentación de la conciencia ciudadana, anula la alteridad con los diferentes cercanos, la solidaridad con los necesitados y la responsabilidad con el conjunto de la ciudad.

\section{La ciudad de los flujos}

En Ersilia, para establecer las relaciones que rigen la vida de la ciudad, los habitantes tienden hilos entre los ángulos de las casas [...] Cuando los hilos son tantos que ya no se puede pasar entre medio, los habitantes se marchan: las casas se desmontan; quedan sólo los hilos y los soportes de los hilos. Y aquello es todavía la ciudad de Ersilia, y ellos no son nada.

Italo Calvino

Recorrer la ciudad y sus calles a pie es ahora un asunto de la memoria social, una experiencia que los jóvenes tapatíos del siglo XXI no tendrán por ahora, en los modos y en los 
tiempos como lo acostumbraron generaciones previas. Ha sido un cambio sociocultural en los modos de vivir y transitar en la gran ciudad de Guadalajara, el cual no ha pasado inadvertido para varias generaciones de citadinos que en los años sesenta y setenta satisfacían su curiosidad por el mundo andando y husmeando por los distintos espacios urbanos que se ofrecían a los cuatro vientos y en constante expansión.

¿Cómo los habitantes de la urbe tapatía de hoy han modificado las formas de hacerse propia su ciudad? ¿En qué se han modificado principalmente? ¿Cómo recorren actualmente la ciudad sus habitantes, qué usan, en qué tiempos, cuánto dinero gastan para trasladarse, qué fronteras internas y simbólicas atraviesan? ¿Qué narrativas prevalecen de la ciudad de antaño y de las nuevas fisonomías de la urbe? Preguntas que no aceptarían una respuesta simple y uniforme, tampoco una tipología que sólo dé cuenta de números y estadísticas, dejando de lado la experiencia humana, el mundo de vida de sus plurales habitantes. No trataremos de responder todas estas preguntas, sino sólo hacer algunas reflexiones alrededor de ellas.

En el apartado anterior vimos que la experiencia de vivir en la zona metropolitana de Guadalajara, con esta diversidad de mundos sociales, se evidencia polarizada y contradictoria, particularmente desde la década de los años setenta. Así, un aspecto que resulta de interés revisar para evidenciar algunos cambios de la esfera sociocultural acontecidos en la ZMG son las trayectorias y movimientos cotidianos de las personas, así como los modos de usar y apropiarse de la ciudad al realizarlas.

Los tapatíos de los años setenta tenían a la mano dos tipos de ciudad para moverse y transcurrir en su vida cotidiana: la del centro histórico y territorial, una ciudad que podía conocerse y recorrerse todavía al paso y al trote que nos permitían nuestros pies. Recorridos peatonales que por las 
calles del centro cifraban su placer en la actividad de las compraventa de mercancías y, cuando se podía, del disfrute de la charla cafetera y de la visita cinematográfica. Ver la ciudad era cuestión de transitarla a pie, todavía en lo que se relaciona con esta ciudad o la parte de la metrópoli en que se estaba convirtiendo la Guadalajara tradicional.

Desde los años cincuenta, por lo menos, se conformaba otra ciudad confundida con la antigua y tradicional: la ciudad de los flujos. Este otro tipo de ciudad se fundía y se combinaba con espacios y rutas de la antigua ciudad. La nueva ciudad era de apetito más voraz y crecía toda alborotada y salvaje, con sus industrias y comercios, y su "avenidismo"9 como plataforma de la modernidad, así como con el aumento cada vez mayor de la población que llegaba desde el interior del estado y de otros aledaños. Ciudad que iba adquiriendo un perfil más industrializado, urbanizado y con una vida comercial en constante crecimiento. Un polo para el crecimiento en el occidente del país. En esta otra ciudad cuyo espíritu era la transformación de las cosas antiguas, los nuevos lugares se hicieron lejanos. La mayor infraestructura vial y aumentar el transporte público fue la solución imaginada y puesta en marcha. La circulación por medio del autotransporte fue la apuesta para mantener la vida urbana. Y el automóvil particular fue el medio y el ideal para usar y ejercer la metrópoli. ${ }^{10}$ Aunque no faltaron iniciativas que procuraban planear de modo más sustentable la vida urbana, no siempre se operaron con éxito.

\footnotetext{
9. Calificativo dado por el escritor Alvargonzález a política urbana que da al automóvil todo el espacio de la ciudad; donde la modernidad se mide por el número de autos que circulan en ella. Cf. "Guadalajara... ¿qué sigue? Avenidismo" en: Reflejos, año II, núm.7, dic.1989-enero 1990, pp. 55-57.

10. Cf. Casillas, Gabriel, "Vialidad y transporte urbanos, en Revista Jalisco, Guadalajara, Jalisco, vol. II, julio-septiembre, 1982, núm.3, p. 2. Para los años ochenta, el autor resalta que: "[...] las actuales modalidades de uso del suelo urbano ocasionan un patrón de asentamientos urbanísticamente anárquico".
} 
Fragmentos urbanos de una misma ciudad: Guadalajara

En la primera e histórica ciudad, el número y el movimiento de los automotores cicatrizaron su fisonomía, contaminaron su aire y aletargaron los movimientos de su población. Camiones y más camiones por rutas y recorridos similares, en una competencia atroz por el pasaje y los tiempos corporativos. En la ciudad que se pretende moderna, comercial e industrializada, de mayores recursos económicos y privilegios, el movimiento de los habitantes no privilegia el modo peatonal, más bien al contrario: lo desalienta y ridiculiza. Ser peatón es ser casi nadie, moverse en un "estatus motorizado" es el ideal que se persigue. La nueva ciudad modernizada requiere de transporte motorizado para ser recorrida, especialmente para dar servicio al trabajo productivo, que lleva obreros y empleados de sus zonas habitacionales a sus centros de trabajo asalariado. También es importante el manejo y traslado de mercancías de todo tipo. La nueva ciudad desea acortar el tiempo de sus rutas y recorridos, el tiempo es dinero y la distracción es inútil. Andar a pie es una pérdida para el capital. Muchos lugares de la ciudad se vuelven invisibles a los habitantes transportados de un lugar a otro. En la ciudad industrial se reconocen los puntos de salida y de llegada, a veces se registran puntos de la ruta transitada, como monumentos, puentes, plazas, glorietas o anuncios espectaculares: fragmentos de la ciudad. ${ }^{11}$

En la vieja ciudad, el tiempo parecía que corría más lento, con ritmos pausados y con horarios un tanto laxos, aunque de todos modos regidos por el insobornable reloj. El mediodía era para la infaltable siesta y la comida en casa. El horario de los comercios y oficinas no era "corrido". Los tiempos y movimientos no apuraban tanto. Aunque había indicios

II. El secretario de Desarrollo Urbano de Jalisco recientemente informó que la metrópoli de Guadalajara “....se extiende sobre unas 45 mil hectáreas y andamos en el orden de los cuatro millones de habitantes" (Público, 14 de febrero de 2003, p. 6). 
que apuntaban a que esto ya iba siendo cada vez menos común. En la década de 1980, la obra pública se centró en el aumento de la vialidad y de la disección espacial para lograr lo anterior. Pares viales, libramientos, túneles, expropiaciones y avenidismo estuvieron a la orden del gobierno en turno. Algunos ejes conectaron y marcaron la ciudad, como las avenidas Lázaro Cárdenas, Federalismo, Patria, Circunvalación; algunas zonas céntricas desaparecieron para ser reemplazadas por nuevos edificios que permanecerían sin ocuparse durante años, como ocurrió en la Plaza Tapatía. Grandes zonas habitacionales se fundaron para plantear supuestas soluciones urbanísticas; Loma Dorada, Miravalle, El Sauz, entre otras zonas de vivienda, son el extremo del crecimiento urbano desmedido. El sur y el norte de la ZMG son el ejemplo de los asentamientos irregulares donde más de 150 colonias carecen de servicios básicos. ${ }^{12} \mathrm{La}$ expansión de la mancha urbana sólo potenció los problemas existentes. Tal fue el caso el sistema de transporte público, que mostró estar completamente superado por la realidad sociourbana. En buena parte, sucedió lo que afirma J. Borja (2000) para las grandes ciudades: "En la globalización la ciudad se extiende, se dispersa, se difumina, se fragmenta, se segrega. La privatización de la urbe es algo muy impresionante, barrios cerrados, centros comerciales en lugar de calles, plazas y mercados [...] por suerte la realidad es contradictoria y gracias a eso se transforma y hay una revalorización de las metrópolis" hoy en día.

La ciudad es un conjunto de estructuras superpuestas, al estilo de un palimpsesto; una ciudad encima de la otra, que deja ver cosas pasadas aún en la superficie de la actual, que interactúa y afecta a la más reciente. La ciudad histórica, territorial, la tradicional, de escala local y con movimiento

12. Cf. Wario, Esteban, "Servicios urbanos en Guadalajara: las lecciones del pasado frente al siglo XXI", en Reflejos, año II, núm. 7, diciembrel989-enero 1990, pp. 42 ss. 
particularmente peatonal y de traslados circunscritos no se extinguió del todo. ${ }^{13}$ La vida barrial sobrevive en algunas zonas, todavía hay quien hace el traslado de personas y mercancías a pie, en medios simples como la bicicleta o con actividades cuya finalidad es la interacción meramente ritual y para la sociabilidad. La vida en el espacio local, en el barrio, sigue aún en la actualidad aportando a la mayor parte de la población la vitalidad y la diferencia del hacer y el habitar la ciudad, que no trae consigo la ola de prácticas y políticas globalizadora, ${ }^{14}$ que lo que pretenden es reconstruir las ciudades para una élite, por lo que se vende una parte de la ciudad y se esconde y abandona el resto. ${ }^{15}$ Sin embargo, la ciudad que permanece con mil oficios y chambas de lo cotidiano está documentada, perviviendo y creando su propia memoria colectiva. ${ }^{16}$

Los movimientos y traslados en la actualidad requieren de mapas y certezas que se apoyan en instrumentos y guías para la orientación en el espacio urbano y metropolitano. Un mapa de la ciudad es un artículo imprescindible para ordenar el caos por el que se transita en la actualidad. Lo moderno se vuelve inconmensurable y enredoso, la guía urbana es la bitácora de nuestro desconocimiento de la ciudad. Ya no es posible abarcarla toda, se escogen secciones, rutas, lugares específicos, horarios convenientes. Se organiza el movimiento de acuerdo a los destinos y a los medios disponibles para

13. Cf. Doñán, J. José, “46I años después”, en Público, I4 de febrero de 2003. 14. Jesús Martín Barbero (2002:143) abunda al respecto: "El espacio social donde mejor se expresa el sentido de la dinámica que, desde lo popular, da forma a nuevos movimientos urbanos es el barrio, en cuanto territorio de despliegue de la resistencia y la creatividad cultural"... Al barrio hay que considerarlo "....como espacio de reconocimiento y construcción de identidades sociales”... El barrio es un "...mediador fundamental entre el universo privado de la casa y el mundo público de la ciudad...”.

15. García Canclini (1999: 168).

16. Periódicos como Público, Mural y El Informador ofrecen frecuentemente a los lectores tapatíos crónicas y reportajes de oficios, vida barrial y tradiciones citadinas que aportan la fuente histórica a esta faceta citadina de lo popular. 
recorrer o atravesar la ciudad. Las aproximadamente 185 rutas actuales del transporte público no facilitan el transitar por la urbe. La ciudad se va reconociendo por las trayectorias recorridas, por los vistazos fugaces que la ventanilla del autotransporte nos permite realizar. Ni el taxista logra el reconocimiento de toda la metrópoli. Su intuición es tan grande como la ciudad, eso es lo que le permite llegar y regresar de los lugares destino de la clientela.

En la ciudad actual, nadie sabe con certeza si todo sigue igual allá afuera de la casa de uno, en la colonia vecina, en el trabajo y en la escuela, en la ruta y en la esquina que nos aguarda. La interdependencia en los movimientos es cada vez más grande y más poderosa. El orden y desorden que vivimos es para todos, y no obstante, se experimenta de modo diverso y en desigualdad de oportunidades, recursos y acceso a privilegios. Vivir en las grandes ciudades como Guadalajara puede hacerse de modos muy diferentes y contrastantes. ¿Qué lo favorece? Principalmente el origen y posición de clase social. Acceso a recursos, oportunidades crecientes, contactos con realidades locales e internacionales, privilegios por herencia y distinciones adquiridas por la posesión de capital de diverso signo acumulado. El movimiento de la población por la ciudad está, entonces, condicionado por la posesión de recursos económicos y el acceso a recursos materiales y tecnológicos para realizar el traslado de personas y mercancías, así como por la ubicación espacial de su actividad económica y la zona de su vivienda y espacio de cotidianidad.

No obstante, la utilización del automóvil ha orientado y marcado permanentemente la ciudad. Su crecimiento numérico ha sido mucho más significativo que el de la población. En 1970 el llamado parque vehicular contabilizaba $80 \mathrm{mil}$ unidades, para 1980 eran más de 220 mil y para los 90 rebasó el medio millón de automotores. En el año 2000, la zona metropolitana de Guadalajara albergaba más de un 
millón de automóviles que saturaban sus calles, particularmente las que cruzan el centro histórico; y, hasta cierta medida, es su uso y la carga ideológica que acarrea consigo la que dicta un estilo de vida urbano para los aproximadamente cuatro millones de personas cuya vida transcurre en esta ciudad. No todos los tapatíos adultos son choferes de autos, pero todos sufren sus consecuencias. ${ }^{17} \mathrm{El}$ transporte público es productor de caos y, en los últimos años, un factor más de control demográfico: por la cantidad de muertes provocadas. ${ }^{18} \mathrm{Ni}$ el tren ligero ni los nuevos pares viales o las vías rápidas han dado la solución integral al movimiento por la ciudad; la situación en este aspecto pareciera estar fuera del control, aunque algunos analistas y críticos observan aciertos urbanísticos. ${ }^{19}$

La ciudad parece estar destinada a satisfacer los deseos de los automovilistas, según lo ha mostrado la obra pública en los últimos decenios. Hay quien sugiere que la obra pública en Guadalajara ha sido un sinónimo de la construcción de pasos a desnivel y apertura de nuevas vialidades. ${ }^{20}$ Una obra que resulta onerosa y excluyente ya que beneficia sólo a $30 \%$ de la población, que es la poseedora de autos. Paradójicamente, la inversión pública y privada en transporte público es casi nula. La ciudad se vuelve más cara para los que no tienen auto a su puerta, que tienen que desplazarse

17. Cf. Arana C., Marcos, "Su majestad el automóvil" en El siglo XX, así lo vimos, así lo vivimos. Publicación del periódico El Informador, 19 de diciembre de 1999, Guadalajara, Jalisco, pp. 6-7.

18. Cf. Cruz, Omar, "Andando el camino"; Navarrete, Antonio, "Una cadena sin final”; y Zúñiga, Andrés, "Los estigmas de un servicio”, todos en 460 años de ser tapatíos. Suplemento del Mural, jueves I 4 de febrero de 2002, Guadalajara, Jalisco, PP. 23 y 24. Estos reportajes dan cuenta de los problemas del transporte público en Guadalajara, las muertes ocasionadas en los últimos años y algunos datos del número de autos en circulación.

19. Cf. Wario R., Víctor, "Década 198I-1990. Nuevo liderazgo, nuevo rumbo", en El siglo XX, así lo vimos, así lo vivimos. Publicación del periódico El Informador, 19 de diciembre de 1999, Guadalajara, Jalisco, pp. 15-17.

20. Cf. Mar de la Paz, Eduardo “La ciudad del automóvil”, en Público, I0 de diciembre de 2002, Guadalajara, Jalisco, p. 19. 
a sus lugares de trabajo un promedio de diez kilómetros y tomarse un tiempo aproximado de 30 a 40 minutos en el traslado. Pareciera que el automóvil es la fuente de inspiración para la planeación urbana de Guadalajara. La poderosa presencia del automóvil ha logrado la pérdida de espacios públicos como parques, áreas verdes, calles barriales, plazas y lugares como las banquetas para desplegar las artes de andar y recorrer la ciudad. Avenidas como Vallarta, Patria o López Mateos, por ejemplo, son escaparates del derroche que se invierte en autos de gran lujo. Andar en bicicleta nunca fue tan peligroso como en la actualidad. ¿Ciclopistas? Una utopía por realizarse. La palomilla de chavos ya no convive en la calle o en el llano futbolero, ahora lo hace, si acaso, en algún parque semiseguro, en las plazas comerciales, y los jóvenes más inquietos en los antros y en refugios de mala nota. Pero el automóvil - y el uso que se le da- no es el único culpable de los cambios en los modos de usar y apropiarse de la metrópoli.

También resulta importante en la manera de usar la ciudad la experiencia acumulada sobre la violencia urbana, que va a depender de los medios de transporte, el tipo utilizado, los horarios de los desplazamientos, el entorno urbano en el que se habita; ya que vivir en un coto cerrado no será lo mismo que hacerlo en una colonia popular o un barrio depauperado del centro histórico o de la periferia urbana. En la actualidad la vivencia del miedo a recorrer la ciudad, ya sea a pie, en bicicleta o en automotores (taxis, camiones, motos, tren ligero, autos particulares) es generalizada, pero con distinta intensidad según los sectores sociales. Cada vez más la nota roja de los periódicos y los noticiarios televisivos no se refieren de manera exclusiva a grupos sociales ajenos y distantes, a los barrios tradicionalmente tenidos por "bravos" o "peligrosos"; ahora abarcan toda la urbe y todos los sectores sociales. El fantasma del miedo anda por toda la metrópoli. 
¿La ciudad de los años setenta era tan contrastante como la de la actualidad? En cuanto al movimiento de la población, no lo era en tal dimensión y envergadura. La diferenciación en las opciones del movimiento y el viaje era menos marcada, y la oportunidad de ejercer y usar la ciudad era también menos excluyente. Sin embargo, no era tampoco entonces una sociedad horizontal y democrática. La diferenciación social y la distinción en las prácticas sociales y estilos culturales eran evidentes e inobjetables.

La Guadalajara de los años setenta se asemeja más a la ciudad actual que a la ciudad del cambio hacia la modernización de los años cincuenta. La ciudad de principios del siglo XXI es en gran parte un resultado de los procesos generados en los años setenta y ochenta. En la actualidad, la ciudad moderna e industrial se superpone a los vestigios de la ciudad histórica territorial, y en gran medida lo logra hacer por las acciones $\mathrm{u}$ omisiones de los actores políticos y urbanos principales de las últimas dos décadas. En este empalme de ciudades diversas, la ciudad actual contiene un rasgo que fue desarrollándose a escala mundial y que comparte con otras grandes ciudades: los flujos de comunicación y de información. Este tipo de ciudad bautizada como "informacional" o "comunicacional" es la que en la actualidad está permitiendo otro tipo de movilidad de los habitantes urbanos, no sólo en lo que se refiere al desplazamiento físico de personas y mercancías, sino a los procesos de producción de redes de comunicación e intercambio de información que hacen prescindible la interacción cara a cara e innecesaria la relación simultánea en el mismo espacio territorial (García Canclini, 1997 y 1999). El acceso diferencial a los medios de comunicación e información es una característica más de la diferenciación y la exclusión que modela la actual sociedad y modos de vida urbanos en Guadalajara. Tener acceso al cable para la televisión o el Internet, el uso de tecnologías de comunicación satelital o medios de almacenamiento y 
distribución masiva de información se ha convertido no sólo en una distinción y marca de estatus, sino en un recurso necesario en la competencia por los beneficios económicos, los privilegios sociales y la movilidad permanente. Esta cualidad de la ciudad comunicacional lleva a una heterogeneidad en los modos de vivir y significar el territorio, en las formas de asumir los modos de pertenencia y de configurar las identidades sociales (Martín Barbero, 2002: 273-277).

La ciudad histórica, la ciudad moderna industrializada y la ciudad comunicacional conviven en el tiempo pero no en todos los espacios territoriales, ya que sus habitantes las ejercen de modo diferencial y no de manera integral. La movilidad de los "managers" internacionalizados, cuya actividad y espíritu son de corte cosmopolita, sólo transita en los espacios urbanos que les competen y requieren, seleccionando y construyendo los apropiados. Lo que no se usa para sus efectos de operación y realización se pueden dejar deteriorar y depositar en el olvido del folclor local. En todo caso, delegan o compran los servicios que requieren. Los ciudadanos no cosmopolitas y excluidos de los beneficios económicos y privilegios sociales se conforman y/o se restringen, en todo caso, al uso de la ciudad pre-informacional, con recursos limitados y modos de desplazamiento y comunicación atrasados tecnológicamente, con interacciones cara a cara y usos intensivos de los espacios urbanos de carácter público, como son las calles, plazas, parques, templos y en general los variados centros urbanos localizados al interior de la metrópoli. La tendencia a la globalización de las metrópolis como Guadalajara tiene modos de inserción y adaptación no del todo funcionales, y más bien parece mayor la dificultad que los logros obtenidos. La ciudad de los flujos parece patinar sin mucha dirección. Y las historias que dan cuenta de ello tienden al romanticismo de un paraíso perdido, o bien, le apuestan a la refundación de corte neoliberal. 
Fragmentos urbanos de una misma ciudad: Guadalajara

\section{De la ciudad arrebatada a la ciudad olvidada}

$$
\begin{array}{r}
\text { ¿Avanzas con la cabeza siempre vuelta hacia atrás? —o bien- } \\
\text { ¿Lo que ves está siempre a tus espaldas? —o mejor- ¿Tu viaje } \\
\text { transcurre sólo en el pasado? }
\end{array}
$$

Italo Calvino

Uno de estos males de nuestro tiempo, como señala Jordi Borja (1997), es la leyenda negra que cubre a las grandes ciudades, que permite diagnosticar su inviabilidad y declarar su muerte próxima:

Aunque a los urbanitas-cívicos nos complazca recordar aquello que "el aire de la ciudad nos hace libres", la realidad urbana actual más bien nos lleva a citar lo de "malos tiempos de la lírica" [...] Las prácticas sociales parecen indicar que la salida es hacerse un refugio, protegerse del aire urbano no sólo porque está contaminado sino porque el espacio abierto a los vientos es peligroso (p. I).

Una leyenda que anuncia la desurbanización de la ciudad o la urbanización sin ciudad. Hoy en día, Guadalajara es una metrópoli, ${ }^{21}$ la segunda ciudad más poblada de México. Y, como gran ciudad mexicana, en crisis. Este hecho contrasta con las representaciones que se elaboran sobre su pasado e identidad:

[...] emergiendo en magnificencia del Valle de Atemajac, como en la felpa del estuche, Guadalajara, Perla Blanca de Occidente, dibuja el amparo de un cielo con tonalidades de turquesa, la aguda silueta de sus altas torres y el vasto perfil de su superficie urbanizada... Pero Tapatía romántica y apasionada, temeraria y emotiva... es caricia y halago en el

21. Se considera que Guadalajara logró tener un crecimiento controlado hasta 1970. A partir de entonces, la conurbanización de los cuatro municipios de la zona metropolitana (Guadalajara, Zapopan, Tlaquepaque y Tonalá), generó el crecimiento no controlado y planificado (véase Ramírez Sáiz, 1998: 33-42). 
perfume de rosas que lleva el aire; en la nítida blancura de sus rectas calles tachonadas de rejas, en el suave verdor de sus jardines y patios interiores, donde crecen arrayanes y naranjos, madreselvas y jazmines cercados de canceles coloniales... (citado en Gastaldi y Ruizesparza, 1998: 7).

Estas son narrativas que se construyen a partir del presente. $\mathrm{El}$ acto de recordar es selectivo: se interpreta y construye sentido; se selecciona, calla o se dicen "verdades" a medias; se olvida, enfatiza o carga de emotividad lo que se busca transmitir. Así, a la Guadalajara de ayer se le ve como una ciudad hermosa, y a la de ahora como una ciudad en crisis. Dos representaciones que, como construcciones socioculturales, idealizan lo que fue y ya no es, y magnifican los problemas que enfrenta y la condenan: "la ciudad que no vale la pena [...] que muere con la congestión" (Ignacio Díaz Morales), la que "perdió su identidad y se parece a cualquier otra" (Víctor Arauz) (citados en Nava, 1992: 595-598). De hecho, la mayoría de los cronistas locales ${ }^{22}$ escriben sobre la ciudad que se perdió y se extraña:

Muchas veces me ha sucedido que recordando a familiares cercanos o amigos queridos que han trascendido ya el paso por el valle, he sentido un ansia irresistible de volverlos a ver y disfrutar de su presencia. Así me pasa también con la ciudad y el barrio que envolvió mi vida, con aquellos cercanos bosques que todavía no eran parques o colonias absurdas, antinaturales, o con aquellos caminos y carreteras viejas y

22. La literatura escrita por cronistas locales es muy abundante. Baste mencionar, por ejemplo, un artículo de Juan José Doñan que aparece en el periódico Público del I de marzo de 2000, que cita algunos autores que escribieron, a partir de la década de los cincuenta, sobre el pasado de Guadalajara y sus continuas pérdidas: Narraciones tapatías de Enrique Francisco Camarena, La imagen de un hombre de Federico Ochoa, Adiós, Guadalajara de Salvador Mora Morán, Aquella Guadalajara de María Luisa Sánchez Vaca de Bancalari, Las huellas de mi caminar del doctor Delfino Gallo, Analco ayer, hoy y siempre de Francisco Escalante Moreno, entre otros (véase Arte y Gente, suplemento del periódico Público, p. 8). 
Fragmentos urbanos de una misma ciudad: Guadalajara

nuevas que aún no eran avenidas intransitables. [...] Esa es la ciudad sorprendente y soberbia, quizá ya decadente, que nos disponemos a recorrer añorando lo que ya no está, lo que no logró permanecer entre nosotros, es decir, de lo que sólo han quedado murmullos... murmullos de nostalgias... (Hernández Larrañaga, 200I: 21 y 22).

Recordar alimenta las representaciones sociales sobre la identidad de la ciudad. Su fisonomía, calles, casas y edificios, los antiguos barrios y colonias, monumentos, glorietas y fuentes, cárceles y panteones, comercios e industrias $\mathrm{y}$, en general, su sociedad y costumbres, la vida festiva y el quehacer cotidiano, se convierten en el motivo de esta remembranza. En este recorrido se busca resaltar la belleza de la ciudad y la tranquilidad de su vida en el pasado, pero como un acto de protesta frente a la modernización y el presente de Guadalajara, una metrópoli y, como tal, lugar de múltiples contactos, intercambios y actividades.

¿Cómo se recuerda a esta Guadalajara idealizada? El primer tema de conversación es la Guadalajara que históricamente ha sido el centro de una vasta región occidental, la cual "[...] formó, configuró y afianzó esa región y su concepto" (véase Vázquez, 1992: 580). Este papel histórico fue paulatinamente cambiando a lo largo del siglo XX y, de manera acelerada, a partir de la década de los setenta con la llegada de capitales de otras zonas del país y del extranjero, pero también por el desarrollo propio de las distintas entidades que históricamente conformaron la región y que ahora tejen sus propias redes de intercambio y comunicación. ${ }^{23} \mathrm{La}$ industrialización trajo consigo la configuración de nuevas redes económicas y políticas en todo el país, lo que alteró su papel como centro - político, cultural, comercial y de servicios— de esta "vasta región" (véase de la Peña, 1986: 75).

23. La región Occidente estuvo conformada por el noroeste (Nayarit, Sinaloa y Sonora) y el centro-occidente (Jalisco, Colima, Aguascalientes y algunas porciones de Michoacán, Guanajuato y Zacateas) (véase De la Peña, 1986: 47). 
Actualmente Guadalajara sigue siendo "la segunda ciudad del país en términos de sus intercambios comerciales y la tercera por el volumen de su producción industrial" (Ramírez Sáiz, 1998: 40). ¿Será así en un futuro no tan lejano? En la actualidad, la globalización de la economía ha generado nuevos reacomodos conformando de manera selectiva una red de nodos selectivos - territorial y socialmente discontinuos- entre ciudades, sectores productivos y manos de obra (Castells, 1997). ¿Es Guadalajara una de estas ciudades que se prepara y busca competir en esta nueva geografías de la economía y la política? ¿Realmente se invierte en ella con este fin? La insuficiencia de la inversión pública parece indicar lo contrario. ${ }^{24}$ Sin embargo, en el imaginario, este atributo - Guadalajara, centro regional- sigue funcionando sobre todo cuando se busca remarcar "la diferencia" como añorada autonomía, de manera particular respecto a la capital del país, ya que se considera que gran parte de los males que aqueja a la ciudad fueron, y son, consecuencia de que las autoridades y los habitantes perdieron el control de su desarrollo: "Las decisiones que se han asumido sobre la ciudad las han tomado muchas veces los tapatíos: no siempre acertadas por cierto. Pero ya no, por lo menos en sus líneas generales, ni aquellas de mayor peso" (Vázquez, 1992: 584). ${ }^{25}$

24. Juan Manuel Ramírez Sáiz (1998) señala que existe una desproporción entre el ritmo constante de crecimiento de la población y el de los ingresos municipales sobre todo a partir de 1994, cuando el incremento de los ingresos "dejó de ser superior al de la inflación" (p. 48). En relación con los egresos, señala un incremento en los gastos administrativos en detrimento de la obra pública y el gasto en inversión (p. 52)

25. Esta cita se refiere al periodo 1940-1950, cuando las autoridades buscaron la colaboración de la población en la planeación y modernización de la ciudad. Con este fin se estableció, en 1943, el Consejo de Colaboración Municipal donde participaron empresarios, colegios de profesionistas y las principales organizaciones de trabajadores (Vázquez, 1989) y, en sus inicios, la Junta Vecinal como un mecanismo de co-financiamiento para la construcción de los servicios públicos (López Moreno, 1996: 337). 
"La culpa es de los otros, de los de fuera" puede ser una queja que desvíe la atención de un tema de especial relevancia, como es la necesidad de planear e invertir en el desarrollo urbano de Guadalajara para no sólo detener sino revertir el proceso de deterioro de la ciudad.

A Guadalajara también se le identifica como una ciudad moderna que se ha resistido a perder su "toque provinciano" porque, por lo menos hasta la década de 1970, fue pensada, construida y planeada por "gente conocida" que gracias a las alianzas matrimoniales lograba "cuidadosamente conservar el poder y la preservación de la unidad, la pureza y la homogeneidad de los grupos" (véase Vázquez, 1992: 580); o por gente que se conoce porque comparte las tradiciones en los antiguos barrios de la ciudad:

Lo que sí es innegable es el ambiente provinciano que esa gente le dio a Guadalajara: las costumbres, las fiestas populares, las diversiones, los barrios, los casinos, las tertulias y otras muchas manifestaciones sociales dan fe de que, en todos los niveles, la ciudad capital de Jalisco, la segunda ciudad de México, no dejaba por completo las costumbres pueblerinas, se negaba a adoptar su carácter citadino. Eso, sin lugar a dudas, representaba el encanto, ése era el secreto para adquirir el toque romántico, caballeresco y regio (Petersen, 1990: 27).

Todos estos relatos de pérdidas se escriben pensando en los problemas que enfrenta Guadalajara como resultado de un desarrollo urbano que, como afirma Amalia Signorelli (2001) sobre la mayoría de las ciudades contemporáneas, "tiende a uniformar [...] y no deja posibilidad de uso autónomo y creativo a los habitantes" (p. 8). Este planteamiento no es del todo nuevo, por el contrario, recuerda un tema clásico de la sociología urbana: las grandes ciudades como lugar de la individualización, del anonimato y la anomia (Wirth, 1988; Anderson, 1975; y Keller, 1975). Ciertamente, en las grandes ciudades los encuentros son fugaces y con mucha 
gente; no se conoce a todos y se está expuesto a múltiples mensajes y formas de comunicación en el tiempo y en el espacio (Hannerz, 1986 y 1992). Por eso, en este tipo de relatos se añora la Guadalajara construida "por nosotros y para nosotros"; ya que se rechaza, precisamente, la heterogeneidad social y cultural que actualmente la caracteriza. Pero, ise puede decir que en el pasado Guadalajara era una ciudad de familiares y conocidos? Desde su fundación fue una ciudad construida por los españoles pero, también, un lugar donde vivían comunidades indígenas y a donde trajeron negros ${ }^{26}$ para servirles, lo que dio lugar, desde sus inicios, al mestizaje, a pesar de las leyes y decretos que buscaron evitarlo:

Prohibimos en todas partes de nuestras Indias que se sirvan los negros y negras, libres o esclavos, de indios o indias [...] Ordenamos y mandamos que se guarde esta prohibición, pena de que si el negro o negra fueren esclavos, le sean dados cien azotes públicamente por la primera vez, y por la segunda se le corten las orejas. [...] Y ordenamos que los dueños de esclavos o esclavas no les consientan, ni den lugar a que tengan indios ni indias, ni se sirvan de ellos y cuiden que así se haga, pena de cien pesos, en que no puedan alegar ignorancia, ni falta de noticias... (citado en Chávez Hayhoe, 1991: 24).

Una ciudad "de nosotros, para nosotros aunque no todos seamos iguales" es la base para la construcción de otra de sus caracterizaciones: "Guadalajara, "ciudad criolla". ${ }^{27}$

26. Arturo Chávez Hayhoe (I99I) señala que durante el siglo XVI la mayoría de los esclavos era de origen africano: "Escribía el señor Mota y Escobar a principios del siglo XVII, en 1606 aproximadamente, que en Guadalajara 'el servicio común de que se sirven (los habitantes de ella) son mulatos y negros esclavos, que el día de hoy hay más de quinientos, sin otros libres de este linaje" (p. 15). Esta cifra no es nada despreciable sobre todo si se considera, para esos años, el mismo número de españoles (Calvo, 1992: 18).

27. Jaime Tamayo y Alejandra Vizcarra (2000) describen la cultura criolla tapatía de la siguiente manera: "En Guadalajara propiamente y en menor escala en el resto de Jalisco, se ha asentado una cultura 'criolla' que, a diferencia del reto del 
Desde el punto de vista de los grupos hegemónicos, se podía convivir porque las diferencias respondían a un orden socialmente normado y jerarquizado (los indios en sus antiguos pueblos y barrios; la ciudad, para los españoles y sus descendientes), y culturalmente sancionado por las características físicas y el color de la piel:

La gallardía y la valentía de los hombres de Guadalajara y la belleza y la gracia de sus mujeres, son proverbiales; y las demás regiones de México no tienen empacho en proclamarlas desapasionadamente... Los hombres en su mayoría son altos, fuertes y hasta barbados: característica física que no se advierte por lo general en las demás regiones del país... Y en cierto modo lo mismo se nota en las mujeres, entre las que si bien abundan las de ojos negros y brillantes, no son tan escasas como en otros lugares las rubias de ojos azules, cualidades que tampoco acusan el tipo mexicano... (Leandro Cañizares, citado por Petersen, 1990: 27).

La diversidad contemporánea, en cambio, se encuentra fuera de "control". En Guadalajara, al igual que en el resto del país y en el mundo entero, se ha diversificado la población y ha cambiado la manera de ganarse la vida. En el mundo contemporáneo la gente se mueve, y cada vez más. A principios de siglo, la posibilidad de vivir en otro lugar era casi nula; hoy en día, sin embargo, la migración, nacional e internacional es una experiencia que forma parte de las trayectorias de vida de casi todos. ${ }^{28} \mathrm{~A}$ Guadalajara, como al estado de Jalisco, vienen a vivir personas de todo el país,

país, no asimila la herencia autóctona y se refleja [...] en la presencia innegable de la moral en la vida social y política del jalisciense, determinada por el peso de la religión católica" (p. 19).

28. Según los censos de población, en 1921, 91\% de la población vivía en su lugar de nacimiento. En la actualidad, menos de $80 \%$ vive en el lugar donde nació (véase INEGI, 1999: 36). En la actualidad esta movilidad no es sólo nacional sino internacional. En el caso de Zacatecas, por ejemplo, $12.2 \%$ de la población de 12 años y más ha ido a buscar trabajo o trabajó en los Estados Unidos de Norteamérica; en Baja California, I I. I\%; en Jalisco, 9.7\%; y en Colima, 7.9\% (Este País, núm. 124 : 56-64 y núm. I25: 60-68, 200I). 
sobre todo provenientes del estado de Zacatecas, Michoacán y el Distrito Federal. ${ }^{29}$ Pero la población local también sale a trabajar o estudiar a Baja California, Colima, Querétaro, Estado de México o a la ciudad de México. ${ }^{30}$

Guadalajara es el destino principal de la migración rural de la entidad y, por supuesto, atrae a población de todo el país. ${ }^{31}$ A esta migración se le considera la principal causa del crecimiento desmedido de la ciudad ${ }^{32}$ y del incremento de los problemas urbanos:

El problema se inició cuando llegaron a Guadalajara personas de la ciudad de México y Monterrey, ya a ellos no les importó nada la ciudad. [...] la armonía se ha ido perdiendo y con ella, con la destrucción de los

29. En 1970, I3\% de la población de Jalisco (560,278 hab.) había nacido en otra entidad federativa. De ésta, $20 \%$ en Zacatecas, $15 \%$ en Michoacán y $11 \%$ en el Distrito Federal (véase INEGI, 1999: 39). Esta proporción se mantiene en el año 2000 (13\%). De los inmigrantes (835, I 2 I hab.), I7\% proviene de Michoacán, I3\% de Zacatecas, I I\% del Distrito Federal (véase INEGI, 200I: 203).

30. En 1970, 645,683 personas se fueron a vivir a otras entidades federativas. De esta población, 19\% eligió como lugar de destino el DF, I5\% se fue a vivir a Baja California y $9 \%$ al Estado de México (véase INEGI, 1999: 39). En el año 2000, un poco más de 726 mil personas habían nacido en Jalisco pero vivían en otra entidad federativa. De esta población, $44 \%$ se dirigió al Estado de México (recordemos que en esta entidad se da el mayor crecimiento -en el territorio y de la población- de la ciudad de México) y II\% al DF, lo que, en conjunto, representa $56 \%$ de la emigración de la entidad. Baja California fue el destino de $23 \%$ de la emigración (véase INEGI, 200I: 197-2II).

31 . Se considera que $73.3 \%$ de la migración a la entidad se dirige a la ciudad. La mayoría proviene del mismo estado de Jalisco (80\%) y solamente $20 \%$ de otras entidades federativas. Sin embargo, esta tendencia comienza a frenarse pues algunas ciudades medias, como Puerto Vallarta, Lagos de Moreno y Zapotlán el Grande, comienzan a recibir población migrante de manera significativa (véase Ramírez Sáiz, 1998: 38).

32. De 1970 a la fecha, la población de la zona metropolitana de Guadalajara (ZMG) ha crecido $120 \%$. La tasa global de crecimiento en los años setenta fue de $51.6 \%$, en los ochenta de poco más de $25 \%$ y en los noventa de $14 \%$. La población de Zapopan se ha quintuplicado en los últimos 25 años, la de Tlaquepaque se ha triplicado y Tonalá es el municipio que más rápidamente ha crecido: "Al inicio de la década de los setenta, su población era de 24,648 habitantes y en 1995 se había multiplicado por II, llegando a 271,969 habitantes" (véase Ramírez Sáiz, 1998: 36). Sin embargo, Guadalajara sigue siendo el municipio más poblado de la ZMG pues en ella vive un poco más de $50 \%$ de la población de la ZMG. 
Fragmentos urbanos de una misma ciudad: Guadalajara

edificios y conjuntos habitaciones, se fue la identidad, la sensación de sentirse ligados al suelo en donde se nació, a la casa grande. El amor a la ciudad, a lo que es nuestro y a lo que somos, es lo que se ha perdido (Víctor Arauz, citado por Nava, 1992: 596-597).

Para algunos, la llegada de los de "afuera" convierte a Guadalajara en una ciudad "arrebatada", "ajena", "extraña":

La ciudad no es de todos sino de cada fracción social, de cada gueto. Entonces se convierte en la ciudad de nadie, de esas que no se pueden conocer, y se vuelve insegura, pero ajena, también extraña... lo cual quiere decir también pobre. No es difícil entonces entender por qué nuestra ciudad ha ido perdiendo sus imágenes de la memoria... sus tradiciones... sus espacios colectivos... su identidad urbana... su unidad... La ciudad ajena, la que vemos pero no sentimos está ganando terreno: está fragmentada, ¿perdida? (Cuauhtémoc de Regil, “Descripción de la ciudad”, Público, 18 de marzo).

A los tapatíos les gusta recordar la Guadalajara provinciana, "cuando era nuestra", por el costo que toda gran ciudad mexicana tiene que pagar: la contaminación del ambiente, el congestionamiento vehicular, los desplazamientos problemáticos por la ciudad, la carencia e insuficiencia de los servicios urbanos, la inseguridad y todo aquello que dificulta construir el sentido de pertenencia y la experiencia gratificante de la ciudad misma (véase Safa, 1998). Todos estos problemas, que son la base para pensar que la ciudad se encuentra en crisis, sostienen una última caracterización, "Guadalajara, la ciudad olvidada". Este último atributo responde a un reclamo a las autoridades locales, y a sus habitantes, no sólo por lo poco que hacen por la ciudad sino también por decisiones poco acertadas:

[...] la falta de una cultura conservacionista parece ser el principal obstáculo para la preservación de los espacios y perfiles urbanos que 
conforman esa identidad. No es que no le importe a alguien, pero son tan pocos - somos tan pocos-, que parece no importarle a nadie. Excluyendo las excepciones que confirmarán la regla; todo se conjuga, la soberbia e ignorancia de unos propietarios mercantilistas e incultos - por decir lo menos - la ingenuidad de unas autoridades casi siempre relajadas, representadas invariablemente por empleados mal pagados y por tanto vulnerables, y lo casi imperdonable, la elasticidad del criterio de los grandes arquitectos y constructores - no se escapa ninguno-, tan proclives a justificar cualquier acto de grosera urbanofagia en tanto sean ellos los beneficiaros del atentado a nuestra casa (Hernández Larrañaga, 200I: 384).

Para concluir este reclamo, Javier Hernández se pregunta, ¿qué hacer para no quedarse "en la crítica improductiva y estéril"? En la literatura que busca elaborar un catálogo de las pérdidas que ha sufrido Guadalajara, predomina una intención conservadora y preservacionista, políticamente poco importante e ineficaz para intervenir en la preservación, mejoría y cambios que la ciudad requiere. Los retos de las grandes metrópolis muchas veces nos hace subestimar la importancia de preservar, como parte de los proyectos de modernización de la ciudad, sus "lugares" (Augé, 1993), porque favorecen la construcción de ciudadanías:

La ciudad es, o debería ser, un sistema de lugares, es decir de espacios con sentido [...] Promover la integración quiere decir que todos estos lugares y elementos deben contribuir a la identidad de la ciudadanía. $\bigcirc$ mejor dicho, a las identidades. Cada grupo debe encontrar espacios y lugares, signos y señales, con los que se pueda identificar. Reforzar la identidad de grupo (de edad o de género, barrial o social, de orientación cultural o sexual, étnico o religioso) no va contra la integración global de la ciudad, sino que generalmente la facilita. Producir sentido mediante la identificación con los elementos materiales y simbólicos del entorno supone contribuir a la cohesión interna de los colectivos sociales, pero también su visibilidad en el magma urbano (Borja, 1998: 27). 
Lo importante de pensar y escribir sobre Guadalajara no es instalarse en la añoranza del paraíso perdido, sino resolver los problemas del hoy para imaginar su futuro. El reto es muy grande. Hacen falta estéticos y novedosos proyectos que engendren la Guadalajara del futuro y, junto a ellos, políticas urbanas que permitan recuperar el espacio público, las plazas, los lugares de encuentro, los barrios y vecindarios, como una forma de construir ciudad.

\section{Re-ligar fragmentos urbanos}

$\mathrm{Si}$ - como hemos visto- Guadalajara encierra muchas ciudades, lo que toca no es elegir cuál de ellas es la más apropiada para la vida de sus habitantes. Es un hecho que no podemos volver al pasado, porque lo que ahí encontraremos son sueños no realizados y enterraríamos el futuro; pero también es un hecho que no podemos rescatar el presente sin construir puentes entre la memoria del ayer y los sueños del mañana. Hemos podido observar que la ciudad construida genera o inhibe procesos de ciudadanía. Si la ciudad es habitada por la diversidad, tenemos que recuperarla no para resaltar la desigualdad, sino para generar espacios abiertos de convivencia plural que permitan re-ligar mundos, para edificar puentes que permitan conectar oportunidades y nivelar las disparidades. Los urbanistas requieren diseñar vías rápidas — no sólo para transportar mercancías- sino que acorten las distancias del encuentro humano, cultural y societal. Todos quisiéramos habitar y transitar en la ciudad amable que dicen que fue Guadalajara. Pero para ello es urgente urbanizar la desigualdad social erigiendo pasos a desnivel que no se conformen con conectar privilegios y aislar la marginalidad, sino al contrario: que fomenten el flujo y tránsito ágil de la diversidad humana y que acorten las distancias económicas y tecnológicas que recrudecen las desigualdades de clases. La tendencia a invertir en nuevas 
geografías que contribuyen a la fragmentación, la exclusión y el aislamiento con el otro no podrán ser las soluciones para equilibrar las diferencias y menos para desterrar el miedo y la violencia que vacían la habitabilidad ciudadana que se requiere como cimiento de la convivencia urbana. Es necesario regularizar las carencias, acortándoles a los más pobres su camino al progreso y la modernidad. Es necesario desdibujar las fronteras y derruir las murallas que inhiben la solidaridad social y la conciencia ciudadana. Es necesario recuperar los espacios abiertos, como territorios de expresión humana para regenerar la comunidad metropolitana y desterrar el tribalismo salvaje. Es necesario conectar vías por donde fluya el encuentro, que no sepulten la interacción humana, la historia y la identidad; sino que provoquen nodos viales donde se practique la alteridad cultural, esto es construir centros culturales y no sólo pasos a desnivel. Es urgente re-ligar los fragmentos de ciudad que se encuentran dispersos en Guadalajara para generar una ciudadanía comprometida y solidaria. A los habitantes de la ciudad nos corresponde inventar nuevas formas de estar juntos y nuevos encuentros que sirvan de cemento a la confianza; tornar el miedo, de un estado de aislamiento, en un estado de solidaridad; rehabilitar, y si es necesario reinventarnos, la memoria histórica que admita que nuestras raíces están tejidas en el mestizaje español-indígena-negro, para que sus ramas crezcan tan fuertes y tan altas que permita a los tapatíos ser el árbol donde, sin perder sus raíces profundas y plurales, anide una identidad universal basada en los derechos humanos. Sólo fortaleciendo y aceptando nuestras múltiples identidades podemos dejar de preocuparnos por fortalecerlas para procurar la alteridad de las diferentes identificaciones que habitan la ciudad. 
González, Álvaro, "Guadalajara... ¿qué sigue?/ Avenidismo”, Bibliografía en Reflejos, año II, núm. 7, 1990, pp. 55-57.

Anderson, Nels, Sociología de la comunidad urbana, México, FCE, 1975.

Arana C., Marcos, "Su majestad el automóvil" en El siglo $X X$, así lo vimos, así lo vivimos. Publicación del periódico El Informador, 19 de diciembre de 1999, Guadalajara, Jalisco, p. 6-7.

Augé, Marc, Los "no lugares". Una antropología de la sobremodernidad, Barcelona, Gedisa, 1993.

Borja, Jordi, "Ciudadanía y espacio público", ponencia presentada en Debat Barcelona: Ciutat Real Ciutat Ideal. Significado y función en el espacio urbano moderno, BarceIona, Centre de Cultura Contemporània de Barcelona, 1997.

- Los desafios del territorio y los derechos de la ciudadanía (manuscrito), Barcelona, 1998.

—_, "Nefasto, privatizar la ciudad" (entrevista a Jordi Borja), en La Jornada, 8 de agosto de 2000, México, DF, 2000.

Cabrales, Luis Felipe y Elia Canosa, "Nuevas formas y viejos valores: urbanizaciones cerradas de lujo en Guadalajara", en Cabrales, Luis Felipe (comp.), Latinoamérica: países abiertos, ciudades cerradas, Guadalajara, UdeGUNESCO, 2002, Pp. 93-117.

Calvino, Italo, Las ciudades invisibles, México, Colección Milenium, 1999.

Calvo, Thomas, "Concubinato y mestizaje en el siglo XVII", en Murià, José María y Jaime Olveda (comps.), Sociedad y costumbres. Lecturas históricas de Guadalajara II, México, INAH, 199I, Pp. 47-69.

Carrier, Joseph, De los otros. Intimidad y homosexualidad entre los hombres de occidente y el noreste de México, Guadalajara, Editorial Pandora, 2002. 
Bibliografía | Casillas, Gabriel, "Vialidad y transporte urbanos”, en Revista Jalisco, Guadalajara, julio-septiembre de 1982, vol. II, núm. 3, pp. 2-10.

Castells, Manuel, La era de la información. Economía, sociedad y cultura, Madrid, Alianza Editorial, 1997.

Cruz, Omar, "Andando el camino", en 460 años de ser tapatíos. Suplemento del periódico Mural, Guadalajara, jueves I4 de febrero de 2002, pp. 23.

Cuéllar, José Luis, Renée de la Torre y Daniel Vázquez, El Centro Histórico de Guadalajara. Mesa redonda, Guadalajara, El Colegio de Jalisco-Instituto Cultural Ignacio Dávila Garibi, 200I.

Chávez Hayhoe, Arturo, Guadalajara en el siglo XVI, Guadalajara, Banco Refaccionario de Jalisco, 1953, t. I.

—_, "La esclavitud", en Murià, José María y Jaime Olveda (comps.), Sociedad y costumbres. Lecturas históricas de Guadalajara II, México, INAH, I99I, pp. I5-34.

De Certau, Michel, La invención de lo cotidiano I. Artes de hacer, México, UIA-ITESO-CEMCA, 1996.

Delgado, Manuel, El animal público. Hacia una antropología de los espacios urbanos (XXVII Premio Anagrama de Ensayo), Barcelona, Anagrama (col. Argumentos), 1999.

Doñán, Juan José, “46I años después” (columna: Troche y Moche), Guadalajara, Jalisco, en Público, 14 de febrero de 2003.

García Canclini, Néstor, Imaginarios urbanos, Buenos Aires, Eudeba, 1997.

_-, La globalización imaginada, México, Paidós Mexicana (col. Estado y Sociedad, núm. 76), 1999.

Gastaldi, S. y Óskar Ruizesparza (fotógrafos), Guadalajara, ayer y hoy, Guadalajara, Editorial Ágata-Museo del Periodismo y las Artes Gráficas, 1998.

Hannerz, Ulf, Exploración de la ciudad, México, FCE, 1986. 
, Cultural Complexity. Studies in the Social Organization of Meaning, Nueva York, Columbia University Press, 1992.

Hernández Larrañaga, Javier, Guadalajara: identidad perdida. Transformación urbana en el siglo XX, Guadalajara, Editorial Ágata-El Informador-Secretaría de Cultura de JaliscoPatronato del Centro Histórico de Guadalajara, 200I.

Ibáñez, Eduardo y Daniel Vázquez, Guadalajara: un análisis urbano, Guadalajara, Ediciones de la CCUVG, 1970.

Ickx, Wonne, "Los fraccionamientos cerrados en la zona metropolitana de Guadalajara" y "Nuevas formas y viejos valores: urbanizaciones cerradas de lujo en Guadalajara", en Cabrales, Luis Felipe (comp.), Latinoamérica: países abiertos, ciudades cerradas, Guadalajara, UdeG-UNESCO, 2002, pp. II 7-I 44.

INEGI, Estadísticas históricas de México, México, Aguascalientes, 1999.

__, XII Censo General de Población y Vivienda 2000, Aguascalientes, México, 200I.

Kéller, Susan, El vecindario urbano. Una perspectiva sociológica, Madrid, Siglo XXI, 1975.

Kleniewski, Nancy, Cities, Change, and Conflict. A political Economy of Urban Life, Belmont, CA, Wadsworth Publishing Co., 1997.

López Moreno, Eduardo, La vivienda social: una historia, Guadalajara, RNIU-UdeG, 1996.

Martín Barbero, Jesús, De los medios a las mediaciones. Comunicación, cultura y hegemonía, México, Gustavo Gili, 1987.

, "Mediaciones urbanas y nuevos escenarios de comunicación", en Sociedad, Buenos Aires, Facultad de Ciencias Sociales de la Universidad de Buenos Aires, 1994, núm. 5, pp. 35-48.
Bibliografía 
Bibliografía $\mid-$ Oficio de cartógrafo. Travesías latinoamericanas de la comunicación en la cultura, Santiago de Chile, FCE, 2002.

Mar de la Paz, Eduardo, “La ciudad del automóvil”, en Público, Guadalajara, Jalisco, 10 de diciembre de 2002.

Martínez Casas, Regina, "Una cara indígena de Guadalajara: la resignificación de la cultura otomí en la ciudad". Tesis de Doctorado en Ciencias Antropológicas, México, UAM-Iztapalapa, 2001.

Mons, Alain, La metáfora social. Imagen, territorio, comunicación, Buenos Aires, Nueva Visión, 1994.

Nava, Marco Antonio, "Guadalajara no vale la pena", en Lecturas históricas de Guadalajara. Tomo III: Demografía y urbanismo, Guadalajara, INAH-Gobierno del Estado de Jalisco-UdeG, 1992, pp. 595-598.

Navarrete, Antonio, “Una cadena sin final”, en 460 años de ser tapatíos. Suplemento del periódico Mural, Guadalajara, jueves 14 de febrero de 2002, pp. 24.

Núñez Miranda, Beatriz, Guadalajara, una visión del siglo $X X$, Zapopan, El Colegio de Jalisco-Ayuntamiento de Guadalajara, 1999.

Peña, Guillermo de la, "Mercados de trabajo y articulación regional: apuntes sobre el caso de Guadalajara y el occidente mexicano", en Peña, Guillermo de la y Agustín Escobar, Cambio regional, mercado de trabajo y vida obrera en Jalisco, Guadalajara, El Colegio de Jalisco, 1986, pp. 47-88.

Petersen, Diego (ed.), En el Valle. La construcción de Guadalajara en el siglo XX, Guadalajara, Cámara Nacional de la Industria de la Construcción, delegación Jalisco-Banca Serfin-Intención y Presencia, 1990.

Ramírez Sáiz, Juan Manuel, ¿Cómo gobiernan Guadalajara? Demandas ciudadanas y respuestas de los ayuntamientos, México, Editorial Porrúa-IISUNAM-UdeG, 1998. 
Reguillo, Rossana, "Imaginários globais, medos locais: a Bibliografía construçao social do medo na cidade", en Lugar Comum. Estudios de midia, cultura e democracia, Río de Janeiro, núm. 8, NEPCOM-UFRJ, 1999, PP. I29-I55.

Rosaldo, Renato, "Ciudadanía cultural en San José, California", en varios autores De lo local a lo global. Perspectivas desde la antropología, México, UAM-Iztapalapa, 1991, pp. 67-88.

Safa Barraza, Patricia, Vecinos y vecindarios en la ciudad de México. Un estudio sobre la construcción de las identidades vecinales en Coyoacán, DF, México, Editorial PorrúaCIESAS-UAM, 1998.

Sarlo, Beatriz, Tiempo presente. Notas sobre el cambio de una cultura, Buenos Aires, Siglo XXI Editores, 200I.

Signorelli, Amalia, "Redefinir lo público desde la ciudad", ponencia presentada en el Simposio Internacional: Reabrir espacios públicos: políticas culturales y ciudadanía, México, UAM-Iztapalapa, 2001.

Tamayo, Jaime y Alejandra Vizcarra, Jalisco, México, UNAM (Biblioteca de las Entidades Federativas), 2000.

Torre, Renée de la, "Guadalajara vista desde la Calzada: fronteras culturales e imaginarios urbanos", en Alteridades, México, Departamento de Antropología-UAM-I, 1998, año 8, núm. 15, pp. 45-55.

_- "Religiosidades populares como anclajes locales de los imaginarios globales", en Metapolítica. Siglo XXI, continuidades y rupturas, enero-marzo de 200I, vol. 5, PP. 98-II 7.

_- Los hijos de la luz. Discurso, identidad y poder en La Luz del Mundo, Guadalajara, UdeG-ITESO-CIESAS, 2000.

Vázquez, Daniel, Guadalajara: ensayos de interpretación, Guadalajara, El Colegio de Jalisco, 1989.

_- "La ciudad que perdimos", en Lecturas históricas de Guadalajara. Tomo III: Demografía y urbanismo, Guadalajara, INAH-Gobierno del Estado de Jalisco-UdeG, 1992, pp. 579-586. 
Bibliografía | Walton, John, "Guadalajara: Creating the Divided City", en Wayne Cornelius y Robert van Kemper (comps.), Metropolitan Latin America. The Challenge and the Response, Beverly Hills, Sage, Latin American Urban Research, vol. VI, 1978, pp. 25-50.

Wario R., Víctor, "Década 198I-1990. Nuevo liderazgo, nuevo rumbo", en El siglo XX, así lo vimos, así lo vivimos. Publicación del periódico El Informador, Guadalajara, Jalisco, 19 de diciembre de 1999, pp. 15-17.

Wario, Esteban, "Servicios urbanos en Guadalajara: las lecciones del pasado frente al siglo XXI", en Reflejos, año II, núm. 7, dic. 1989-enero 1990, pp. 42 y ss.

Wirth, Louis, "El urbanismo como forma de vida", en Bassols, Mario et al. (comps.), Antología de sociología urbana, México, UNAM, 1988 [1938].

Zúñiga, Andrés, "Los estigmas de un servicio", en 460 años de ser tapatíos. Suplemento del periódico Mural, Guadalajara, jueves 14 de febrero de 2002, pp. 23. 